\title{
Pfizer breaks from merger mentality as others chase leads
}

It was less than two years ago that the pharmaceutical giant Pfizer made headlines when it acquired the drugmaker Wyeth for a cool $\$ 68$ billion. But these days Pfizer is generating a buzz for mulling over a different way to bump up its bottom line: shedding some of its nonpharmaceutical divisions. The potential plan has not won over all industry analysts, some of whom say that scooping up smaller companies with strong drug pipelinesparticularly those in developing markets-still offers the best path to profits.

The takeover of Genzyme by Sanofi this past spring was only the latest in a string of companies combining, going back to the Merck-Schering-Plough and Roche-Genentech fusions in 2009. These strategic rearrangements of industry titans have largely been a response to looming patent losses. Over the next two years, patents will expire on more than a dozen blockbuster drugs with combined annual sales of about $\$ 50$ billion, according to the research organization EvaluatePharma in London.

Notably, New York-based Pfizer will bear the brunt of the so-called 'patent cliff' this year, when it loses its exclusivity rights for the cholesterol fighter Lipitor (atorvastatin) - the best-selling medication in the US-and the antacid Protonix (pantoprazole). More than two thirds of the company's portfolio-worth more than $\$ 35$ billion-will be at risk in the next three years owing to patent expirations, according to EvaluatePharma.

The company could increase its profits by becoming a leaner machine and focusing on neuroscience, vaccines and other core therapeutic areas with the greatest growth potential according to David Amsellem, a New York-based analyst with Piper Jaffray. He cites Sanofi's decision to sell its dermatology business to focus on high-growth areas as an example of this type of strategy. "You're going to see these kinds of transactions become increasingly common," says Amsellem.

But not all analysts are so keen on the divestment approach. "I doubt that Pfizer will split completely into component parts," says Jamie Davies, head of pharmaceuticals and healthcare analysis at Business Monitor International in London. "This was speculation to test the market, which wasn't overly favorable." An analysis by Sector \& Sovereign Research, based in Stamford, Connecticut, suggests that a Pfizer spin-off that sells off-patent and established products would fail because of a lack of revenue from new medicines. When contacted by Nature Medicine, Pfizer said that it hopes to complete its review of its portfolio during the second half of the year and is still determining the optimal mix of businesses that it can appropriately fund and manage.

\section{Shop 'til you drop}

Breaking up is hard to do, they say. As such, it's perhaps not surprising that many companies are continuing the shopping spree, looking for firms to snatch up. Mergers and acquisitions continue to remain attractive to companies seeking to bolster their product pipeline-and save money by consolidating resources and staff. "The biggest advantage in the near term is economies of scale," Amsellem says. "Big pharma has been active on the mergers and acquisitions front, and I would expect that to continue."

There were hints that the spate of major mergers is not over when, in early May, Marijn Dekkers, chief executive officer of the German drug giant Bayer, mentioned that he would consider strengthening the company's healthcare unit by acquiring another drugmaker that generates similar earnings. Dekkers stated on 3 May on Bloomberg television show "Fast Forward" that he'd be open to a merger "if the stars were to be aligned." He tendered that Bayer was coming from a position of strength, saying: "We have a relatively good pipeline compared with the rest of the industry, and we don't have blockbusters coming off patent, either."

Meanwhile, some pharmaceutical companies in North America are setting their sights on midsized generic firms in Central and Eastern Europe and the Middle East. For example, Canadian drugmaker Valeant recently bought out Lithuania’s Sanitas, and New Jersey-based Watson Pharmaceuticals purchased Greece's Specifar. By setting up shop in other nations, US-based companies can tap into emerging markets more effectively, says Damien Conover, an analyst at Morningstar, headquartered in Chicago. "The growth in some of these international markets is stronger than the growth potential in the US right now."

But, given the lack of suitable candidates overseas, the trend will probably not continue indefinitely, says Lindsay Meyer, an investment analyst at Canaan Partners in Menlo Park, California. "This is not sustainable, and the appetite for these companies will eventually go away because the supply is so constrained."

Whether the future will bring more mergers or a deluge of divestitures remains uncertain. Amsellem, for his part, notes the two trends may occur in parallel. "Right now, I think the industry is trying to find its way in this new world order," he says. "One thing I can tell you with almost certainty is that it's not going to look the same two to three years from now."

Janelle Weaver

\section{A shortage link?}

On 19 May, US senator Herb Kohl, a Democrat representing Wisconsin, sent a letter to the chairman of the country's Federal Trade Commission (FTC) to urge the agency to examine the effect of mergers in the pharmaceutical industry on the nation's drug supply. In his letter, Kohl cites a recent Washington Post article reporting "an unprecedented surge in drug shortages in the United States that is endangering cancer patients, heart attack victims, accident survivors and a host of other ill people."

A record 211 medications became scarce last year, triple the number in 2006, and at least 89 new shortages have emerged so far this year. "The megamergers of the past decade may be contributing to these critical drug deficiencies," Kohl states, adding that the disappearance of some companies and the restructuring of drug giants lead to diminished production of older and less profitable products.

The US Food and Drug Administration has policies and procedures to deal with these deficiencies-including importing medications from overseas when necessary. But, in addition to these efforts, Kohl advises the FTC to take shortages into account when enforcing antitrust laws.

Not everyone agrees that the senator's take rings true. Lindsay Meyer, an analyst at Canaan Partners in Menlo Park, California, says, "I don't think you can reduce this simply to consolidation in the industry." The supply of drugs also depends on forecasts of future demand and relationships and contractual issues between hospitals and suppliers, Meyer adds. "There are too many other factors to just boil it down to the pharmaceutical companies' fault."

Janelle Weaver 